\title{
Design, analysis and fabrication of a linear permanent magnet synchronous machine
}

\author{
MONOJIT SEAL* and MAINAK SENGUPTA \\ Department of Electrical Engineering, Indian Institute of Engineering Science and Technology, Shibpur, \\ Howrah 711103, India \\ e-mail: seal.monojit@gmail.com; mainak.sengupta@gmail.com; msg@ee.becs.ac.in
}

MS received 15 March 2016; revised 21 December 2016; accepted 18 April 2017

\begin{abstract}
This paper deals with the design, analysis and fabrication of a $320 \mathrm{~W}, 5 \mathrm{~m} / \mathrm{s}$, 4-pole permanentmagnet-based linear synchronous machine (LPMSM). The design deals with conventional hand calculations followed by design fine-tuning and analysis using standard FEM packages. Fabrication of the machine has been also done at the works of a local small machine manufacturer after procurement of imported permanent magnets (PMs). The work presented here focuses on design and fabrication of LPMSM linor stampings with fixed dimensions and standard available PM tablets with a view to providing simple design guidelines. This prototype forms part of a variable speed linear motor drive that is being developed. The approach presented here might provide new ideas to those researchers who may not have the capability to bear cost of fabrication of lamination and PMs from scratch but would like to manufacture LPMSMs from available stampings and tablet PMs. Additionally, it may serve as a base document for the R\&D personnel in this area.
\end{abstract}

Keywords. Linear permanent magnet synchronous machine; LPMSM—fabrication; design optimisation; finite-element method.

\section{Introduction}

The first record of the use of concept of linear motors can be traced back to the 1840s. While the first proposal was patented in 1841 by Charles Wheatstone, the first linear induction motor (LIM) prototype was patented in 1890 [1]. Since then, linear motors are used commercially in different applications like lifts, elevators, spinning machines, transportation, conveyors, etc., for their capability to cause linear motion without the use of intermediate gears, screws or crank shafts $[2,3]$. Also, with the increase in cost of energy since the 1970s, recent trends favour elimination of losses associated with intermediate stages in energy efficient drives. A significant step towards achieving energy efficiency consists of removing mechanical losses in applications where rotary motion is mechanically converted to linear motion through an elaborate arrangement of crank shafts, ball screws, rack and pinion, etc. Hence the importance of linear motors in direct applications of linear motion $[4,5]$. The availability of permanent magnets (PMs) with considerable energy density and the advent of power electronic converters with digital controllers accelerated the development of high-precision energy-efficient drives in linear motion control $[6,7]$.

*For correspondence
Figure 1 shows a categorisation of the linear alternating current (AC) machines $[2,9,10]$. The present paper deals with the design, analysis and fabrication of a short primary PM-based linear synchronous machine (LSM) and preparing a basis for comparing the performance of the same with a short primary LIM later on. Compared with a LIM, where the stator current provides for both the magnetising and the thrust-producing components of current, in linear permanent magnet synchronous machines (LPMSMs) the PM produces the field flux, thus causing mainly the thrust-producing component of stator current to be drawn from supply. Since, there is no copper loss in the rotor circuit (unlike LIM), for the same output, LPMSM operates at a higher efficiency. High energy density of PMs, along with lower losses, leads to reduction in size and weight too.

Primarily, two different types of constructions are possible for LPMSMs, viz., (i) surface PM based and (ii) buried PM based. A cross-sectional view of the first type having PMs on the surface is shown in figure $2 \mathrm{a}$ while the other with PMs buried inside the mild steel pole is shown in figure $2 b$. In surface mounting arrangement of LPMSM, the yoke (back iron) is made of ferro-magnetic material (usually a steel plate) and the direction of magnetisation of the PMs is perpendicular to the active surface. However, for buried LPMSM, the yoke is made of non-ferromagnetic material(e.g., aluminium) and the 


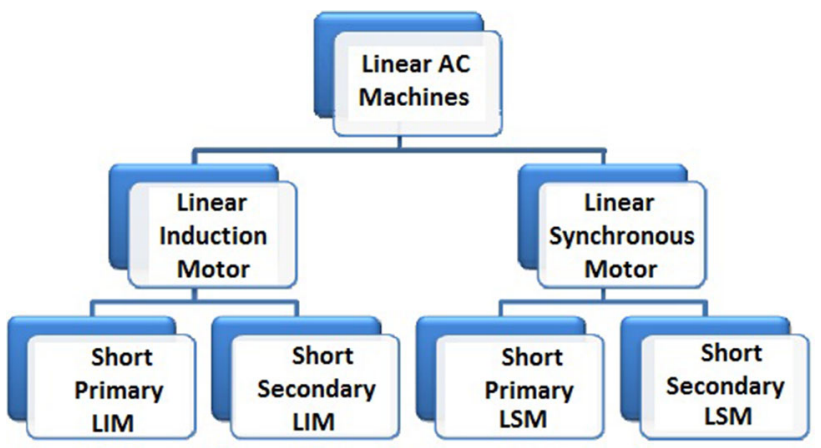

Figure 1. Hierarchy chart illustrating types of linear machines.
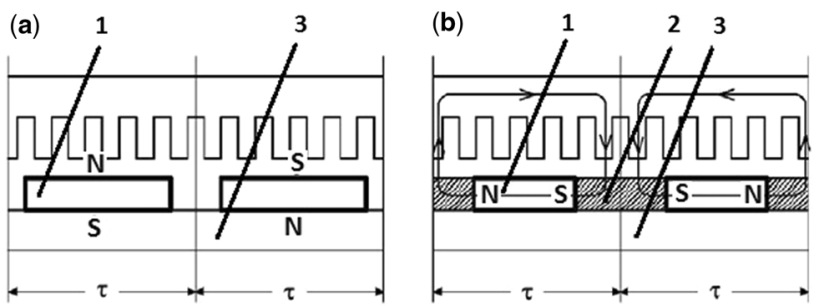

Figure 2. Single-sided flat PM LSMs with slotted armature core: (a) surface PMs and (b) buried PMs. 1-PM, 2-mild steel pole and 3-yoke [8].

PMs are magnetised in the direction of travelling magnetic field $[8,11]$. The present work is on surfacemounted LPMSM, which has been chosen due to the ease of fabrication compared with buried PM type LPMSM.

The importance of LPMSM need not be overemphasised. To add to this, it may be mentioned here that LPMSMs conceptually, design-wise and application-wise are fore runners of Tubular PMSM (TPMSM), which has niche applications in very specialised areas $[12,13]$. The present work is also a part of a research activity to develop TPMSMs - the design of which is protected mostly by patents [14-16]. Thus, the present paper may be treated as significant in two ways: (i) a guidance to researchers in developing real LPMSM from scratch and (ii) providing the basis for subsequent discussions on TPMSMs. Both of these are rarely available in public literature. In the following discussions, the work focuses on design procedure of the machine using limited resources and in spite of various technical and non-technical constraints.

\section{Basic principles}

As is well known, conventional AC polyphase synchronous motors are motors with DC electromagnetic excitation. The rotor rotates at the speed of the rotating magnetic field produced by armature windings. A linear synchronous motor (LSM) is a 'developed rotor' variant of the conventional synchronous motor in which the 'linor' (moving member) is in synchronism with the linearly travelling magnetic field. The thrust (propulsion force) can be generated as an action of

- travelling magnetic field produced by a balanced polyphase winding energised from a balanced polyphase supply.

- steady magnetic field produced by electronically commutated DC excitation to the same polyphase winding using an inverter $[1,8]$.

In an LPMSM, the steady field flux is obtained from (PMs) instead of DC-exited electromagnets. This increases the overall cost of machine fabrication but decreases the weight, size and copper loss. In the present work the PMfield system is kept static while the three-phase armature has been made the 'linor'. For PM-based machines, the difficulty remains in the design of the PM of minimum volume and at the same time preventing demagnetisation of the PMs (arising out of armature reaction). The LPMSM design presented here has a constraint of being fabricated with the same linor stampings as used for previously fabricated LIM [17], i.e., the dimensions of the linor are fixed. In the following sections, the design of LPMSM has been presented [18-20]. The specific references have been cited at appropriate places in course of the design exercise.

\section{Design and analysis of LPMSM}

\subsection{Specifications and selection of main dimensions}

The nominal specifications of the machine are given in table 1 . An efficiency of $\eta=0.85$ and fundamental p.f. $\cos \Phi=0.9$ have been taken as targeted performance indices. This gives an efficiency-power factor product of $\eta \cos \Phi=0.765$. The present prototype has been developed using the dimensions of the laminations used in a previously fabricated LIM in our laboratory [18]. The detailed dimensions of the stampings are shown in figure 3 . This

Table 1. Targeted specifications of the linear PMSM.

\begin{tabular}{lcc}
\hline Quantity & Symbol & Value \\
\hline Synchronous speed & $v_{\mathrm{s}}$ & $5 \mathrm{~m} / \mathrm{s}$ \\
Number of primary phases & $m_{1}$ & 3 \\
Operating line voltage & $V_{\mathrm{L}}$ & $100 \mathrm{~V}$ \\
Operating frequency & $f$ & $50 \mathrm{~Hz}$ \\
Connection & $\mathrm{Y}$ & $\mathrm{Star}$ \\
Number of pole pairs & $p$ & 2 \\
Rated power & $P_{\mathrm{m}}$ & $320 \mathrm{~W}$ \\
Air-gap length & $g$ & $2 \mathrm{~mm}$ \\
\hline
\end{tabular}




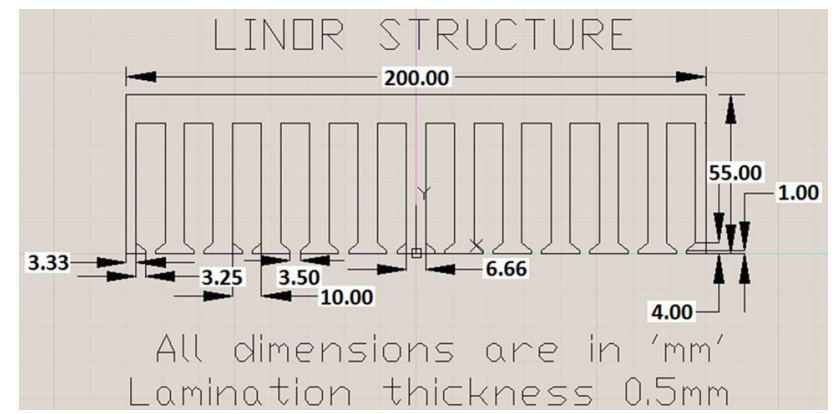

Figure 3. Dimensions of the stamping used for LPMSM.

helps in reduction of overall cost and time of fabrication of machine since a major cost and time involved are those of fabrication of die and of tooling.

The air-gap length is chosen to be as $2 \mathrm{~mm}$ (identical to that of existing LIM), which is a little high, but has to be kept more because of mechanical reasons of (i) providing ample clearance as the linor moves over the rectilinear 'open' track and (ii) the mechanical difficulty of providing a long and 'perfectly level' track.

\subsection{Initial calculation steps}

From table 1, we get

- pole pitch $(\tau)=50 \mathrm{~mm}$ and

- transverse length of primary $\left(L_{\tau}\right)=200 \mathrm{~mm}$. The value of $L_{\tau}$ matches well with that of our chosen stamping (dimension shown in figure 3 ). The voltampere (VA) rating of the machine is

$$
S_{\text {rated }}=\frac{P_{\mathrm{m}}}{\eta \cos \phi} \simeq 420 \mathrm{VA}
$$

Since, series leakage inductance in this machine will be high, the induced e.m.f. at rated speed as obtained, when excited by PMs (without armature reaction), is taken as $80 \%$ of the terminal voltage, i.e., $E_{f}=45 \mathrm{~V}$.

Rated primary current is given by (because of $\mathrm{Y}$ connection) $I_{1}=\frac{S_{\text {rated }}}{\sqrt{3} V_{\mathrm{L}}}=2.41 \mathrm{~A}$. Therefore, VA transferred across air gap is given by, $S_{e m}=3 E_{f} I_{1}=325 \mathrm{VA}$. The calculated values of the different relevant are given in table 2 .

\subsection{Calculations for length and width of magnet}

A linear machine can be considered as the 'developed rotor' form of a conventional (radial flux) rotary machine whose length of rotor in the direction of shaft axis corresponds to width of the linor, i.e., referring to figure 4 , the width is perpendicular to the plane of paper. The length of the linor is along the direction of motion of the travelling
Table 2. Other calculated quantities of the machine.

\begin{tabular}{lcc}
\hline Quantity & Expression & Value \\
\hline Pole pitch $\tau$ & & $50 \mathrm{~mm}$ \\
Coil pitch $w_{\mathrm{c}}$ & $50 \mathrm{~mm}$ \\
Slots/pole/phase $q_{\mathrm{s}}$ & 1 \\
Pitch factor $\mathrm{k}_{\mathrm{p} 1}$ & $\sin \left(\frac{\Pi}{2} \frac{w_{\mathrm{c}}}{\tau}\right)$ & 1 \\
Distribution factor $k_{\mathrm{d} 1}$ & $\sin \left[\Pi /\left(2 m_{1}\right)\right]$ & 1 \\
\cline { 2 - 3 } Winding factor $k_{\mathrm{w} 1}$ & $q_{s} \sin \left[\Pi /\left(2 m_{1} q_{\mathrm{s}}\right)\right]$ & 1 \\
\hline
\end{tabular}

magnetic field. Since, PMs are to be placed along the length and width of the linor, the same will be referred to as length and width of magnet, respectively, in the rest of the text. The height (thickness) of magnet is the dimension along the flux path (i.e., corresponding to radial depth in conventional machine). The design of surface area of PMs is a little critical because of the following constraints:

- dimensions of stampings must be the same as those of previously fabricated LIM.

- commercially available magnetic tablets with standard dimensions are being used to bring down costs.

In case magnets would have been procured as per the designed dimensions (as has been done for some three other rotary machines in this laboratory), the cost of magnets would have increased by a factor of 10 to 15 , since the entire cost of sintering and forming the magnets would then have to be additionally borne.

It is well known that the space-time distribution of the MMF of a symmetrical polyphase distributed winding parameters fed with balanced polyphase AC can be expressed as (2) for forward travelling fields [8]. Considering the fundamental $(v=1)$ alone, the space-time distribution of MMF simplifies to

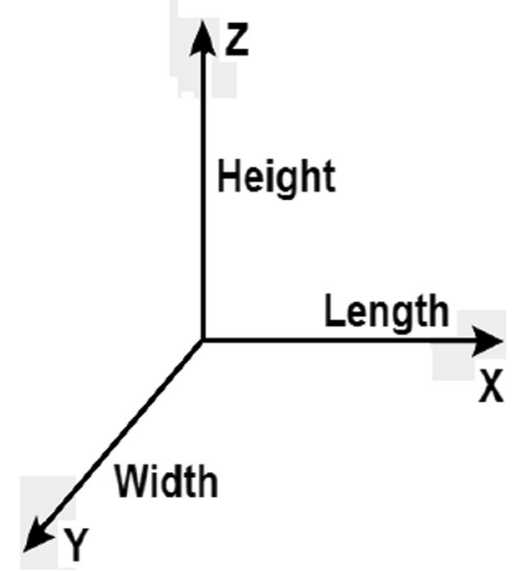

Figure 4. Definition of the dimensions of the LPMSM. 


$$
\begin{aligned}
F(x, t)= & \frac{\sqrt{2} I_{1} N_{1}}{\Pi p} \sin \omega t \sum_{v=1}^{\infty} \frac{1}{v} k_{\mathrm{w} 1 v} \cos \left(v \frac{\Pi}{\tau} x\right) \\
& +\frac{\sqrt{2} I_{1} N_{1}}{\Pi p} \sin \left(\omega t-\frac{1}{m_{1}} 2 \Pi\right) \sum_{v=1}^{\infty} \frac{1}{v} k_{\mathrm{w} 1 v} \\
& \times \cos v\left(\frac{\Pi}{\tau} x-\frac{1}{m_{1}} 2 \Pi\right)+\ldots \\
& +\frac{\sqrt{2} I_{1} N_{1}}{\Pi p} \sin \left(\omega t-\frac{m_{1}-1}{m_{1}} 2 \Pi\right) \\
& \times \sum_{v=1}^{\infty} \frac{1}{v} k_{\mathrm{w} 1 v} \cos v\left(\frac{\Pi}{\tau} x-\frac{m_{1}-1}{m_{1}} 2 \Pi\right) \\
& F(x, t)=\frac{1}{2} F_{m} \sin \left(\omega t-v \frac{\Pi}{\tau} x\right)
\end{aligned}
$$

where $I_{1}$ is the armature phase current, $m_{1}$ is the number of phases, $N_{1}$ is the number of turns per phase and $F_{m v}=$ $\frac{2 m_{1}}{\Pi p} \sqrt{2} I_{1} N_{1} \frac{1}{v} k_{w 1 v}$ while $F_{m}=\frac{2 m_{1}}{\Pi p} \sqrt{2} I_{1} N_{1} k_{w 1}$.

The space-time distribution of the transverse current density of armature line current $a(x, t)$ for the fundamental space harmonic [8] can be obtained by first derivative of $F(x, t)$ in (3) with respect to $x$ coordinate, which gives

$$
\begin{aligned}
a(x, t) & =\frac{d F(x, t)}{d x}=-\frac{m_{1}}{p \tau} \sqrt{2} I_{1} N_{1} k_{w 1} \cos \left(\omega t-\frac{\Pi}{\tau} x\right) \\
& =-\mathfrak{R}\left[A_{m} e^{j \omega t} e^{-j \frac{\Pi}{\tau} x}\right] .
\end{aligned}
$$

It can be shown that [8] the magnitude of transverse current $\left(A_{m y}\right)$ is given by

$$
A_{m y}=\frac{\sqrt{2} m_{1} I_{1} N_{1} k_{\mathrm{w} 1}}{p \tau} .
$$

Considering peak value of air-gap flux density, $B_{m z}=$ $0.7 \mathrm{~T}$ and $A_{m y}=26000 \mathrm{Ac} / \mathrm{m}$, and using (6), output coefficient $\left(\sigma_{p}\right)=0.5 B_{m z} A_{m y} k_{w 1}=9100 \mathrm{VAs} / \mathrm{m}^{3}$ [8].

$$
\begin{aligned}
& \text { The output coefficient } \sigma_{p}=0.5 B_{m z} A_{m y} k_{\mathrm{w} 1} \\
& =\frac{S_{e m}}{v_{\mathrm{s}} \times 2 p \times \text { Total area of magnet' }}
\end{aligned}
$$

This gives total area of magnet along the flux path as

$$
a_{m a g}=\frac{S_{e m}}{\sigma_{p} v_{\mathrm{s}} \times 2 p}=1785.71 \mathrm{~mm}^{2}
$$

The widths of the 'linor' and the PMs on the track are the same. Now, to find out the width of PMs (or linor), one has to consider a number of technical and commercial issues. As, mentioned earlier, linor stampings of definite length
( $L_{\tau}=200 \mathrm{~mm}$ ) of previously fabricated LIM is used to reduce cost and time of tooling. Also, commercially available standard magnetic tablets of specified dimensions are to be used and that should fit the dimensions of the design. They are the practical constraints in this case.

Since $L_{\tau}=200 \mathrm{~mm}$ and number of pole pairs $(p)=2$, length of each magnetic pole $=\tau=50 \mathrm{~mm}$. Therefore, the width of PMs, $L_{i}\left(=\frac{\text { total area of magnet }}{\text { length of magnet }}\right)$, is obtained as $36 \mathrm{~mm}$. This chosen length of the magnet matches well with the commercially available magnets and our requirements. The output coefficient $\left(\sigma_{p}\right)$ and transverse current $\left(A_{m y}\right)$ are obtained as $9052 \mathrm{VAs} / \mathrm{m}^{3}$ and $25862 \mathrm{Ac} / \mathrm{m}$, respectively, after repeated iterations. The flux per pole is found to be $\Phi_{m}=\frac{2}{\pi} \tau L_{i} B_{m z}=0.8 \mathrm{mWb}$. The different values obtained are shown in table 3 .

\subsection{Determination of magnet thickness}

Designing of a PM involves accounting for the effect of demagnetisation ATs due to lagging armature current and choice of an appropriate magnet from the off-the-shelf available stock of magnet tablets. An optimum design should also ensure cost economy. However, at the same time, for lagging load currents the PMs should not get demagnetised beyond the allowed limit. The magnet has been designed considering an average air-gap flux density $B_{a v}=0.45 \mathrm{~T}$. Applying Ampere's circuital law to the closed flux line in figure 5, we have (8). Applying (8) (where $H_{\mathrm{m}}, H_{\mathrm{g}}, H_{\mathrm{Fe}}$ and $H_{\text {core }}$ are magnetic field intensities and $l_{\mathrm{m}}, l_{\mathrm{g}}, l_{\mathrm{Fe}}$ and $l_{\text {core }}$ are lengths of PMs, air-gap, back-iron and linor, respectively), we get that the total ATs required is nearly 1960 AT (considering $B-H$ characteristics of $\mathrm{NdFeB}, \mathrm{N}-35$, as shown in figure 6 , at temperature $100^{\circ} \mathrm{C}$ ). Neglecting leakage and fringing flux [21], the net magnet thickness (height) is given by

$$
\begin{gathered}
H_{\mathrm{m}} l_{\mathrm{m}}+H_{\mathrm{g}} l_{\mathrm{g}}+H_{\mathrm{Fe}} l_{\mathrm{Fe}}+H_{\text {core }} l_{\text {core }}=0, \\
l_{\mathrm{m}}=\frac{\text { total } \mathrm{AT}}{H_{\mathrm{m}}} \simeq 6 \mathrm{~mm} .
\end{gathered}
$$

Since, a complete magnetic path is considered for calculation as shown in figure 5, the thickness of each magnet is $3 \mathrm{~mm}$. The dimensions of the procured magnetic tablet is $12 \mathrm{~mm} \times 12 \mathrm{~mm} \times 3 \mathrm{~mm}$, and orientation is along thickness of $3 \mathrm{~mm}$.

Table 3. Obtained values of $B_{m z}, A_{m y},\left(B_{m z} A_{m y}\right)$ product and $\sigma_{p}$.

\begin{tabular}{lc}
\hline Design parameter & Value \\
\hline Peak value of air-gap flux density $B_{m z}(\mathrm{~T})$ & 0.7 \\
Magnitude of transverse line current $A_{m y}(\mathrm{Ac} / \mathrm{m})$ & 25862 \\
$B_{m z} A_{m y}$ product $(\mathrm{TA} / \mathrm{m})$ & 18103 \\
Output co-efficient $\sigma_{p}\left(\mathrm{VAs} / \mathrm{m}^{3}\right)$ & 9052
\end{tabular}




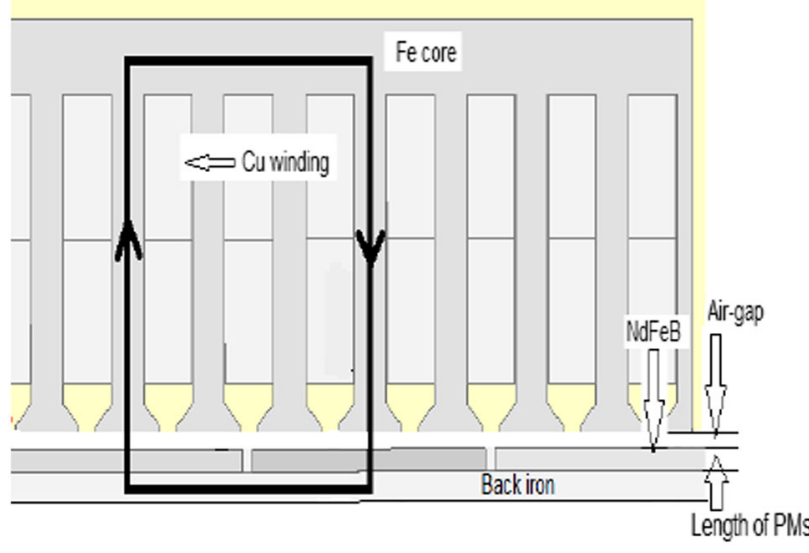

Figure 5. Magnetic circuit considered for LPMSM.

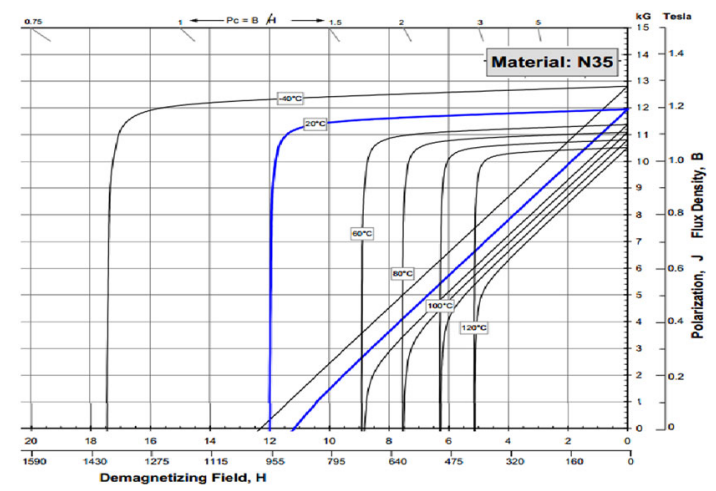

Figure 6. $B-H$ curve for $\mathrm{NdFeB}, \mathrm{N}-35$ grade at different temperatures.

\subsection{Selection of turns per phase and winding arrangement}

From table 3, the transverse current density, $A_{m y}$ is $25862 \mathrm{~A} /$ $\mathrm{m}$. Solving (5), the number of primary turns/phase $\left(N_{1}\right)$ is

$$
N_{1}=\frac{A_{m y} p \tau}{\sqrt{2} m_{1} I_{1} k_{\mathrm{w} 1}} \simeq 254 .
$$

As is evident from figure 3 , the total number of slots $\left(z_{1}\right)$ is 12. This gives number of conductors/phase/slot $N_{s l}\left(=\frac{2 N_{1} m_{1}}{z_{1}}\right)$ as 127. The calculated area of each primary slot $\left[=b_{11}\left(h_{11}+h_{12}\right)+b_{14} h_{14}+0.5\left(b_{11}+b_{14}\right) h_{13}\right] \quad$ is $430.25 \mathrm{~mm}^{2}$ as shown in figure 8 and the effective area available for conductors is $410 \mathrm{~mm}^{2}$. Considering current density $\left(J_{1}\right)$ as $6 \mathrm{~A} / \mathrm{mm}^{2}$, the cross-sectional area of conductor without insulation $S_{\mathrm{c}}=\frac{I_{1}}{J_{1}}=\frac{2.41}{6}=0.4017 \mathrm{~mm}^{2}$. Bare diameter of conductor (without insulation) is obtained as $0.73 \mathrm{~mm}$.

However, the nearest available diameter of conductor (d) with insulation is $0.813 \mathrm{~mm}$ (SWG 21). Seven conductors may be placed widthwise, i.e., $7 \times 0.813 \mathrm{~mm}=$
$8.1 \mathrm{~mm}<10 \mathrm{~mm}$ and 19 conductors may be considered lengthwise, i.e., $19 \times 0.813 \mathrm{~mm}=23 \mathrm{~mm}<41 \mathrm{~mm}$ which is well within the available limits. A double-layer full-pitched winding is used here. Therefore, coil span $=\frac{\text { no. of slots }}{\text { no. of poles }}=3$.

The winding details are given in table 4 . The double-layer winding arrangement in the respective slots and the winding chart for one phase are shown in figure $7 \mathrm{a}$ and $\mathrm{b}$, respectively. Since this linor is that of a 3 -phase machine with $q_{s}=1$, there will be 3 coils out of the 12 coils whose mechanical linear full pitch will be $=9$ slots, while the other 9 coils will have a full pitch of 3 slots. Also, for manual winding, more slot area is allotted to allow slackness and for space required by wedge, slot lining and insulation.

\subsection{Estimation of electrical parameters}

As mentioned earlier, nine coils will have usual overhang length $\left(w_{\text {ov } 9 \text { coils }}\right)=0.5 \tau=25 \mathrm{~mm}$. The overhang measured after fabrication is around $20 \mathrm{~mm}$. The other three coils will have more overhang length as they have coil pitch of nine slots. Therefore, overhang length for three coils $\left(w_{\text {ov } 3 \text { coils }}\right)=45 \mathrm{~mm}$. However, the overhang measured is around $35 \mathrm{~mm}$ as shown in figure $14 \mathrm{a}$.

The length of mean turn for the nine usual coils $\left(L_{\mathrm{mt} 9 \text { coils }}\right)=2 L_{i}+2.5 \tau+2 w_{\text {ov } 9 \text { coils }}=237 \mathrm{~mm}$ and the remaining three coils $\left(L_{\mathrm{mt} 3 \text { coils }}\right)=2 L_{i}+2.5 \times 3 \tau+$ $2 w_{\mathrm{ov}}$ 9coils $=517 \mathrm{~mm}$. The armature resistance per phase for nine coils $\quad r_{1 \text { (9coils) }}=\rho \frac{L_{\mathrm{mt}} \text { 9coils }}{S_{c}} N_{1}=3.25 \Omega$ while the armature resistance per phase for three coils, $r_{1(3 \text { coils })}=$ $\rho \frac{L_{\mathrm{mt} 3 \text { coils }}}{S_{\mathrm{c}}} N_{1}=7.08 \Omega, \quad$ where $\quad \rho=0.02167 \Omega / \mathrm{m} \mathrm{mm}^{2}$ at $75^{\circ} \mathrm{C}$. Therefore, average armature resistance per phase $\left(r_{1}\right)=4.21 \Omega$ (since three of the four coils are of usual pitch and one is of longer overhang) (table 5).

The specific permeance of slot leakage flux path $\left(\lambda_{11}\right)$ for the semi-open slot [8], as shown in figure 8 , is given by $\lambda_{11}=\frac{h_{11}}{3 b_{11}}+\frac{h_{12}}{b_{11}}+\frac{2 h_{13}}{b_{11}+b_{14}}+\frac{h_{14}}{b_{14}}$. For a double-layer winding, $\frac{3 w_{\mathrm{c}} / \tau+1}{4}$ is multiplied to get $\lambda_{11}=3.2968$. The specific permeance of the overhang (end connection) for double-layer, low-voltage, small-power motors is given

Table 4. Winding details of LPMSM.

\begin{tabular}{lc}
\hline Type of coil & Distributed \\
Coil span & Full pitch \\
Number of layers & Double \\
Slots & Semi-closed \\
Connection & Star \\
Phase spread & $60^{\circ}$ electrical \\
Slotting & Integral \\
\hline
\end{tabular}




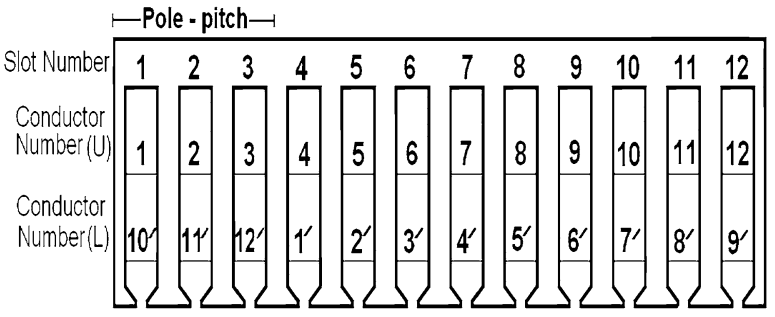

(a)
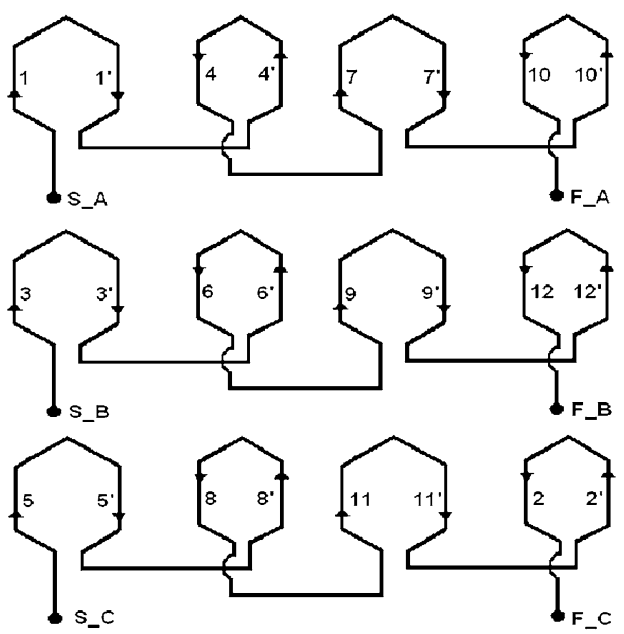

(b)

Figure 7. Double-layer winding arrangement of three phases of LPMSM. (a) Double-layer winding arrangement. (b) Winding arrangement of three phases of LPMSM. $S_{A}, S_{B}$ and $S_{C}$ are the 'start' end and $F_{A}, F_{B}$ and $F_{C}$ are the 'finish' terminals.

Table 5. Calculated values of electrical parameters of LPMSM.

\begin{tabular}{lc}
\hline Electrical parameters $($ per phase) & Values \\
\hline Overhang length $\left(w_{\mathrm{ov}}\right)$ & $30 \mathrm{~mm}$ \\
Length of mean turn $\left(L_{\mathrm{mt}}\right)$ & $0.257 \mathrm{~m}$ \\
Primary resistance $\left(r_{1}\right)$ & $4.21 \Omega$ \\
Slot leakage reactance $\left(X_{11}\right)$ & $3.02 \Omega$ \\
Overhang leakage reactance $\left(X_{1 \text { ov }}\right)$ & $0.20 \Omega$ \\
Differential leakage reactance $\left(X_{1 \mathrm{~d}}\right)$ & $6.05 \Omega$ \\
Armature reactance $\left(X_{\mathrm{a}}\right)$ & $11.47 \Omega$ \\
Primary leakage reactance $\left(X_{1}\right)$ & $9.27 \Omega$ \\
\end{tabular}

by [8] $\lambda_{1 \mathrm{ov}} \approx 0.34 q_{\mathrm{s}}\left(1-\frac{2}{\Pi} \frac{w_{\mathrm{c}}}{l_{1 \mathrm{e}}}\right)=0.1432$, where $l_{1 \mathrm{e}}$ is the length of single-end connections. The specific permeance of differential leakage flux [8], $\lambda_{1 \mathrm{~d}}=$ $\frac{m_{1} q_{\mathrm{s}} \tau k_{\mathrm{w} 1}^{2}}{\Pi^{2} g k_{\mathrm{c}} k_{\mathrm{sat}}} \tau_{\mathrm{d} 1}=6.5981$ where $k_{\mathrm{c}}$ is Carter's coefficient including the effect of slotting of the armature stack. It is given by

$$
\begin{aligned}
& k_{\mathrm{c}}=\frac{\text { slot pitch }}{\text { slot pitch }-\gamma_{1}}=1.1517, \text { where } \\
& \gamma_{1}=\frac{4}{\Pi}\left[\frac{b_{14}}{2 g} \tan ^{-1} \frac{b_{14}}{2 g}-\ln \sqrt{1+\left(\frac{b_{14}}{2 g}\right)^{2}}\right] .
\end{aligned}
$$

Therefore, the primary leakage reactance $\left(X_{1}\right)$ is given by

$$
\begin{aligned}
X_{1} & =X_{11}+X_{1 \mathrm{ov}}+X_{1 \mathrm{~d}} \\
& =4 \Pi f \mu_{0} \frac{L_{i}\left(N_{1}\right)^{2}}{p q_{\mathrm{s}}}\left(\lambda_{11} \kappa_{1 \mathrm{X}}+\frac{l_{1 \mathrm{e}}}{L_{\mathrm{i}}} \lambda_{1 \mathrm{ov}}+\lambda_{1 \mathrm{~d}}\right)=9.27 \Omega
\end{aligned}
$$

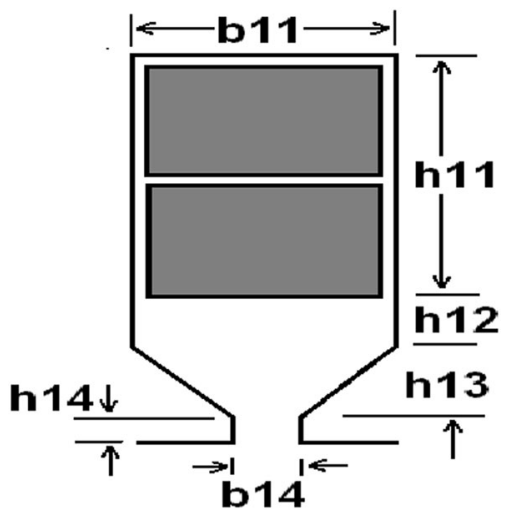

Figure 8. Semi-open armature slots used for single-sided LPMSM [19].

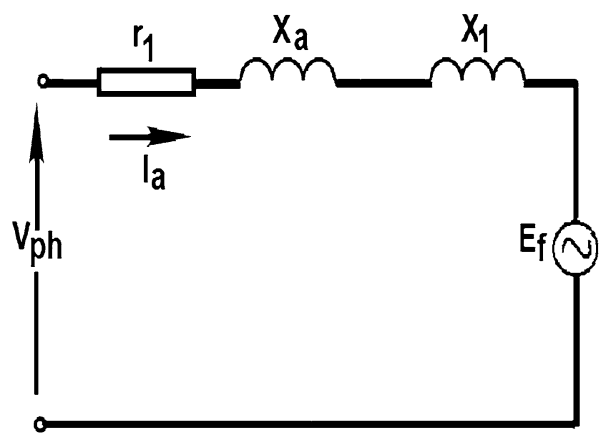

Figure 9. Equivalent circuit for LPMSM.

where $\kappa_{1 X}$ is the skin-effect coefficient for leakage reactance which is $\approx 1$ for small machines. The equivalent circuit and the phasor diagram are shown in figures 9 and 10 , respectively. 


\section{Calculation and design validation using standard FEM packages}

The LPMSM electrical parameters and variables are also evaluated using a standard FEM package for the purpose of cross verification. The practical waveforms of the no-load induced e.m.f. at rated speed obtained for the three respective phases are shown in figure 11(a). The induced e.m.f. reads $50 \mathrm{~V}$, which is in close correlation with the handcalculated value of $46 \mathrm{~V}$. The waveforms of the flux linkages of the three phases are shown in figure 11b. The waveforms of induced e.m.f. and flux linkage of the same phase are

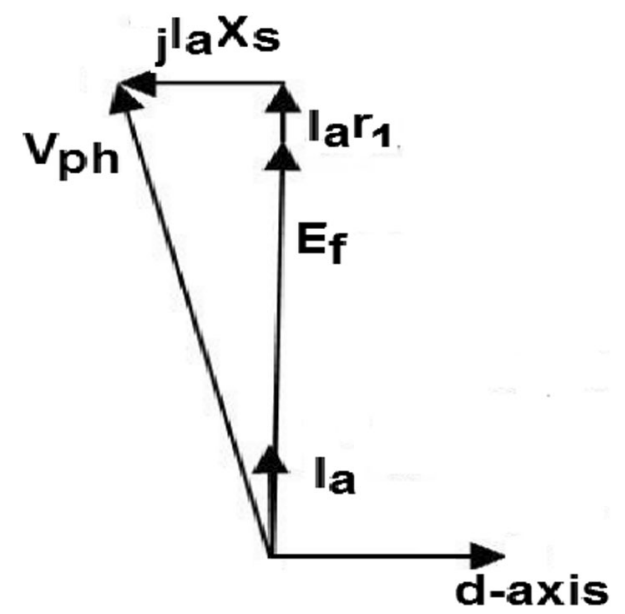

Figure 10. Phasor diagram for LPMSM.

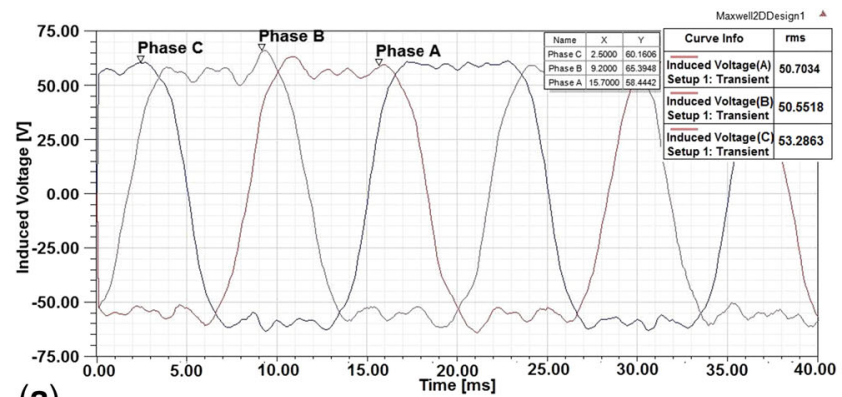

(a)

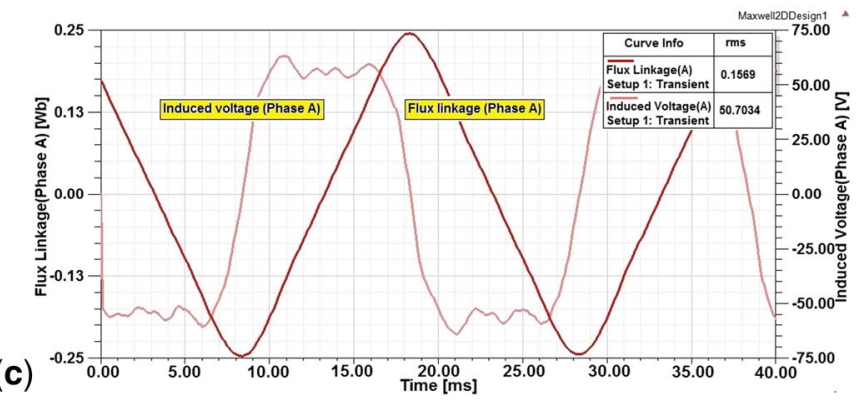

Figure 11. Simulated e.m.f. and flux linkage waveforms of the LPMSM. (a) Three-phase no-load induced e.m.f. in the air-gap at rated speed of $5 \mathrm{~m} / \mathrm{s}$ when excited by PMs. (b) Three-phase flux linkage of the LPMSM at rated speed of $5 \mathrm{~m} / \mathrm{s}$. (c) Variation of flux linkage and induced voltage of Phase A.

shown in figure $11 \mathrm{c}$. It is clearly seen that the back e.m.f. leads the flux linkage by $90^{\circ}$. The plots of magnetic field density and the flux lines over the entire machine at time $=1 \mathrm{~ms}$ at a distance of $5 \mathrm{~mm}$ from initial position are shown in figure 12a and $\mathrm{b}$ respectively. The magnetic field in the air-gap has a maximum value of $0.8 \mathrm{~T}$ under no-load, which is in good correlation with the calculated value. The complete design data sheet of this $320 \mathrm{~W}$, 4-pole, $3-\phi$, rated speed of $5 \mathrm{~m} / \mathrm{s}$ LPMSM is shown in table 6 .

\section{Fabrication of LPMSM}

The designed LPMSM was fabricated at the works of a local small electrical machine manufacturer after procurement of imported PMs (NdFeB-N35). The dimensions of each magnet tablet are $12 \mathrm{~mm} \times 12 \mathrm{~mm} \times 3 \mathrm{~mm}$, and orientation is along thickness of $3 \mathrm{~mm}$. This selection of magnet dimensions and the design of machine is a little tedious, as it tries to adjust the calculations to dimensions of the standard available magnets and the armature stampings used for fabricating LIM. In other words, the dimensions of each tablet should be carefully chosen so that integral numbers of these make a complete 3Dpole. Thus, each pole pitch of $50 \mathrm{~mm}$ length and pole length (lateral) of $36 \mathrm{~mm}$ was made by placing four magnets side by side along the pole pitch length direction and three magnets side by side along the lateral length. The procured magnet tablets and armature stampings are shown in figure 13a and $b$ respectively. Figure 14a shows the armature of short primary of the LPMSM after winding arrangement.

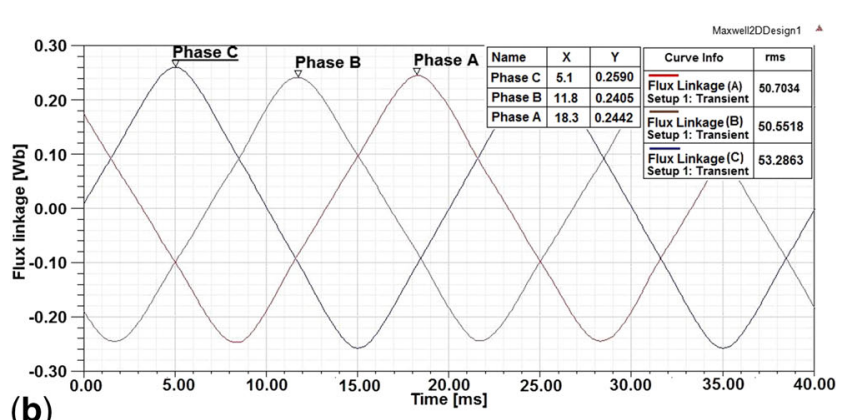

(b)

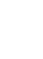




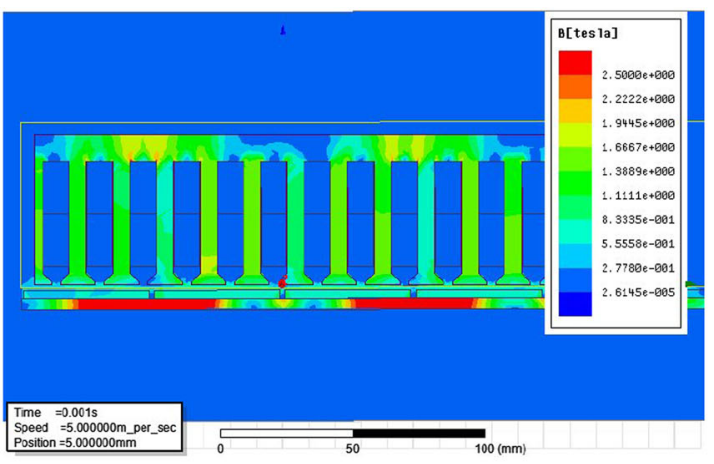

(a)

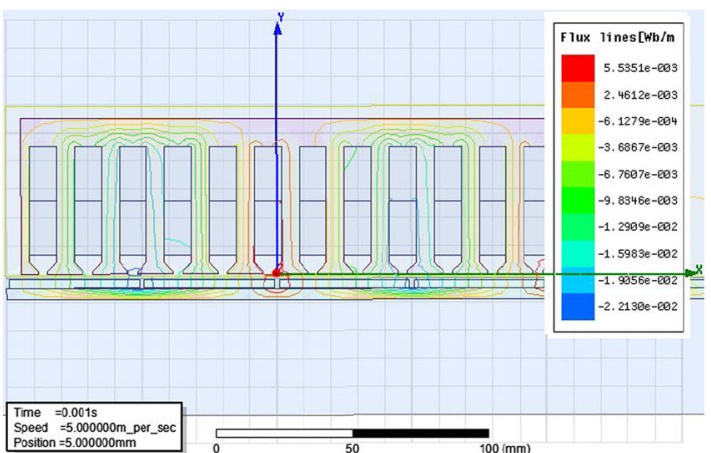

(b)

Figure 12. Simulated magnetic field density and flux lines in the air-gap, core and back-iron along with PMs of the LPMSM. (a) Magnetic field density in air-gap, core and back-iron along with magnet at position $=5 \mathrm{~mm}$, time $=0.001 \mathrm{~s}$ from initial position. (b) Flux lines in air-gap, core, back-iron along with magnet at position $=5 \mathrm{~mm}$, time $=0.001 \mathrm{~s}$ from initial position.

\subsection{Fabrication of track for LPMSM}

The length of the fabricated track is $2 \mathrm{~m}$, out of which magnets are placed along $1 \mathrm{~m}$ length. Width of back iron $\left(=L_{i}+0.1 \tau=36+0.1 \times 50\right)$ is $41 \mathrm{~mm}$. The thickness of the back iron is $10 \mathrm{~mm}$. This is kept equal to the depth of linor core. The magnetic pieces are arranged in $4 \times 3$ fashion to make a pole as shown in figure 14b. The aluminium sheet is of $2 \mathrm{~mm}$ thickness and the width is $\left(L_{i}+2 w_{\mathrm{ov}} \approx\right) 106 \mathrm{~mm}$.

PM-based machines have inherent starting thrust (or torque in the rotary case) problem in the absence of position feedback. Hence, presently a provision has been made for starting the motor as LIM first and then allowing it to 'catch-up' to the LPMSM mode (like the synchronous induction motor). Figure 15a shows a diagram of the yoke. Here, all dimensions are in 'mm'. Figure $15 \mathrm{~b}$ shows the complete track mounted on a wooden base over which the back-iron, magnet and aluminium have been placed. The set-up have been run with open-loop $V / f$ control as shown in figure $16 \mathrm{~b}$.

\subsection{Comparison between LIM and LPMSM}

It is worthwhile to mention the gist of a quick comparison between the existing LIM prototype (previously developed in this laboratory) and this LPMSM, of the same power rating, poles and linor stamping dimensions, here. It shows that there is a significant decrease in the width of the primary of the LPMSM to nearly one-third of that of the LIM. The rated primary current has also decreased from 7.25 to $2.41 \mathrm{~A}$. The armature weight (without housing) of the LPMSM is found to have decreased to one-third the weight of the LIM. However, the calculated cost of fabricating the machine can increase (4 to 5) times with respect to LIM. In this case it has increased (1.5 to 1.75) times since the tooling and die making cost for the
Table 6. Design sheet of the fabricated LPMSM.

\begin{tabular}{lc}
\hline Design Data & Value \\
\hline Number of slots/pole/phase $q_{\mathrm{s}}$ & 1 \\
Winding factor $k_{\mathrm{w} 1}$ & 1 \\
Pole pitch in slots & 3 \\
Coil pitch & Full pitch \\
Armature slot pitch & $16.66 \mathrm{~mm}$ \\
Pole pitch-to-pole shoe ratio & 0.96 \\
Width of armature slot $b_{11}$ & $10 \mathrm{~mm}$ \\
Number of coils & 12 \\
Number of turns per coil & 65 \\
Wire diameter & $0.813 \mathrm{~mm}$ \\
Tooth width & $6.66 \mathrm{~mm}$ \\
Conductor area to slot area $k_{\mathrm{sl}}$ & 0.2 \\
Carter's coefficient $k_{\mathrm{c}}$ & 1.1517 \\
Length of armature (or linor/forcer) & $200 \mathrm{~mm}$ \\
Material of armature & Laminated steel M-45 \\
& $0.5 \mathrm{~mm} \mathrm{thick}$ \\
Air-gap & $2 \mathrm{~mm}$ \\
PM material & NdFeB, $B_{r}=1.21 \mathrm{~T}$ \\
PM height & $3 \mathrm{~mm}$ \\
PM face area & $144 \mathrm{~mm}$ \\
Mass of armature yoke & $2.2 \mathrm{~kg}$ \\
Mass of armature conductors & $2.9 \mathrm{~kg}$ \\
Primary resistance/phase & $3.52 \Omega$ \\
Specific slot leakage permeance $\lambda_{11}$ & 3.2968 \\
Specific permeance of the overhang & 0.1432 \\
$\quad \lambda_{10 v}$ & 6.5981 \\
Specific permeance of differential & \\
leakage $\lambda_{1 \mathrm{~d}}$ & $9.27 \Omega$ \\
Primary leakage reactance $X_{1}$ & \\
\hline & \\
&
\end{tabular}

LPMSM stampings was already incurred earlier for the LIM. Detailed comparison can be made after the set-ups are run continuously. For this two round tracks are presently under fabrication. Also, if a production line is made, the costs will not be this high. 


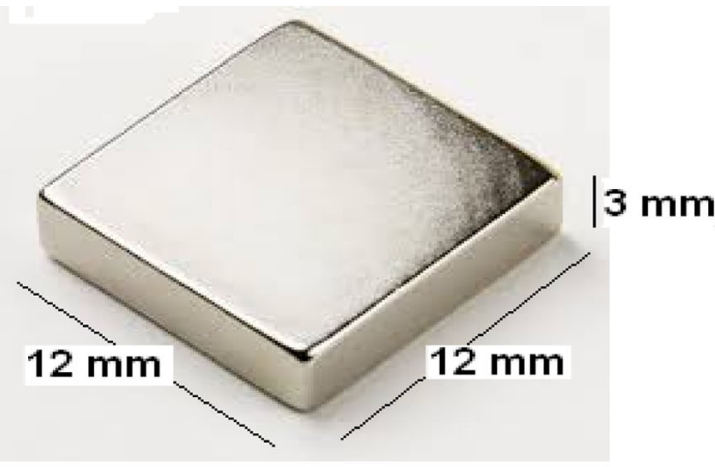

(a)

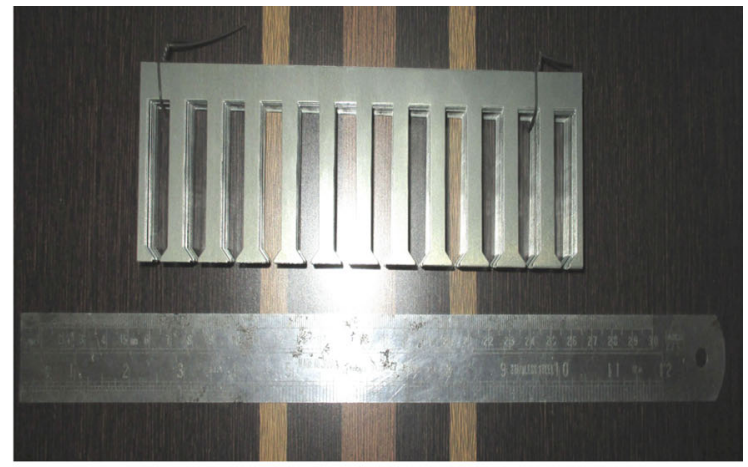

(b)

Figure 13. Photograph of unit PM (NdFeB N-35 grade) and armature stampings of the linor. (a) Dimension of unit NdFeB N-35-grade procured PMs. (b) Armature stamping of the LPMSM.

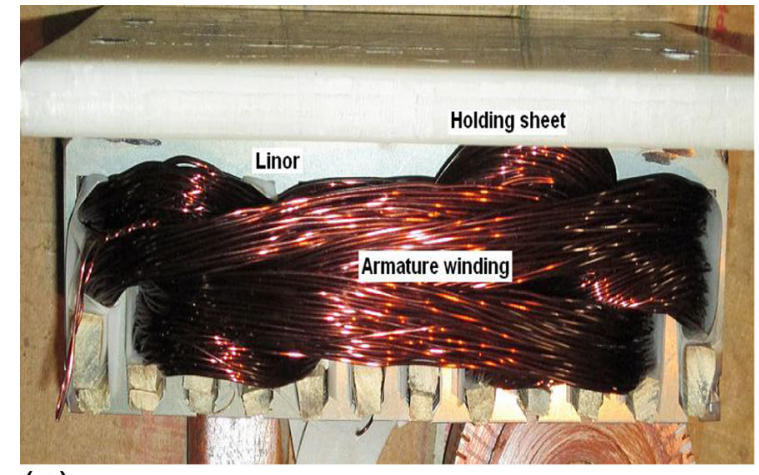

(a)

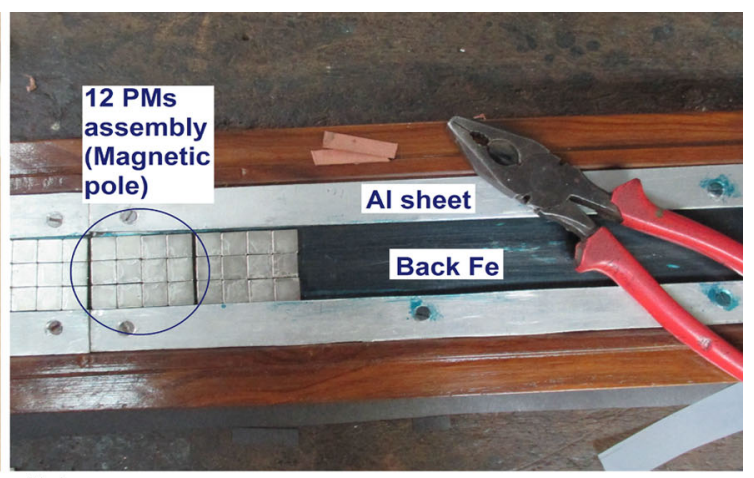

(b)

Figure 14. Photograph of fabricated linor and magnetic poles for the track (formed by PMs assembly). (a) Single-sided short primary of the LPMSM. (b) PMs assembled to form magnetic poles.

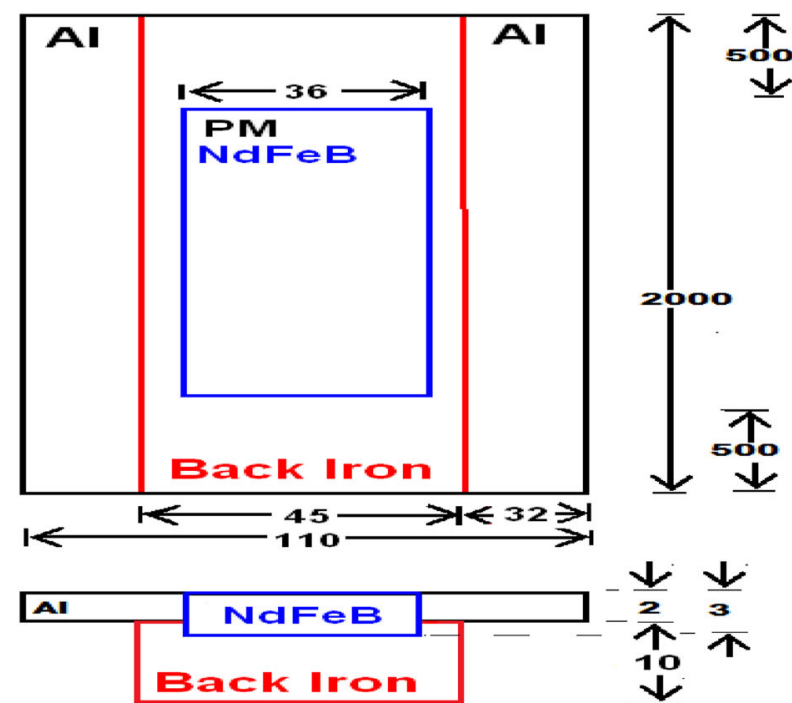

(a)

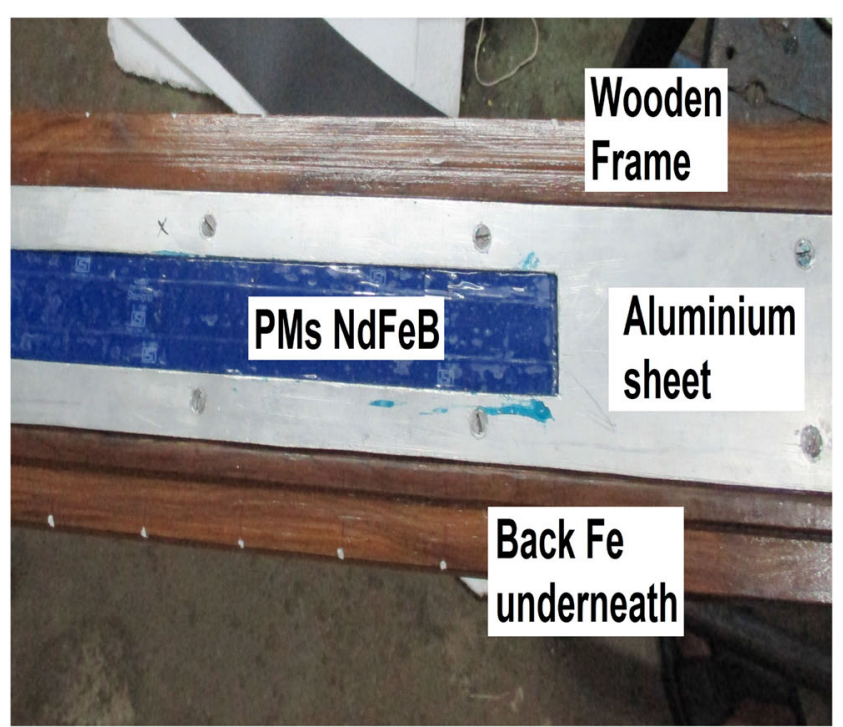

(b)

Figure 15. Dimensions of the track and photograph of the fabricated track. (a) Dimensions of track (yoke) of the LPMSM. All dimensions are in 'mm' (view perpendicular to the direction of propulsion). (b) Wooden base for the yoke with PMs, Al sheet and back iron (top view). 


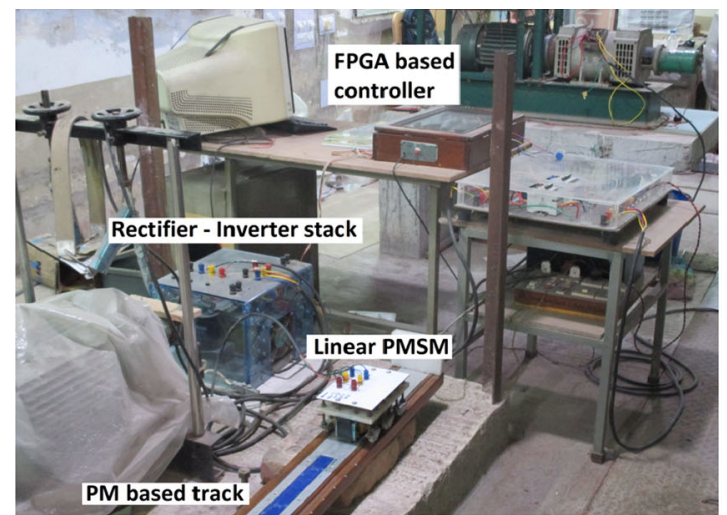

(a)

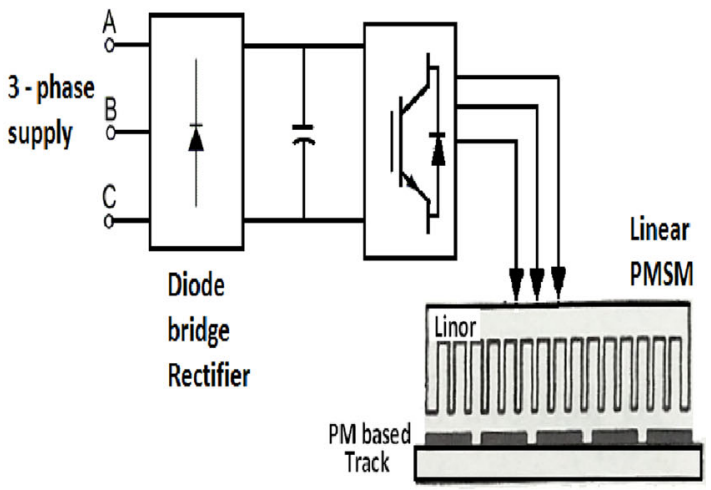

(b)

Figure 16. Photograph and schematic diagram of LPMSM and its set-up. (a) Photograph of LPMSM set-up as run using a digital controller. (b) Schematic diagram of set-up as run under open-loop $V / f$ control.

\section{Conclusions}

The present paper is expected to contribute in two important way: (i) a guidance to interested researchers in developing a real LPMSM from scratch and (ii) providing a basis for subsequent discussions on TPMSMs. Thus, in this work design and fabrication of a 3- $\Phi$, 4-pole, $320 \mathrm{~W}$, $5 \mathrm{~m} / \mathrm{s}$ surface-mounted LPMSM have been carried out. For ease of fabrication and for cost reduction the design starts with the dimensions of available stampings used previously for fabrication of a LIM prototype that exists in the laboratory $[18,22]$. The nominal ratings are also kept same. The design has been optimised and verified with the help of standard FEM packages. The linor has been fabricated and winding has been completed. The yoke (track) is fabricated with $\mathrm{NdFeB} \mathrm{N}$-35-grade PMs. The fabricated LPMSM may be used in various advanced control speed drives for fast dynamic response and maximum reliability. Predicted values obtained from conventional analytical calculations are validated through FEM packages at different conditions. The predicted values and the practically obtained values are found to be in very good agreement with each other.

\section{Acknowledgements}

The authors wish to thank the COE (MDAMD), IIEST, Shibpur, and TEQIP-II for the funds support. The authors acknowledge the role of Mr Kaushik Pyne and the entire staff of G.E. Motors for their technical support in fabricating the motor. The support received from the research colleagues in the Advanced Power Electronics Lab and particularly Mr N Dutta, Project Technical Assistant, APE Lab, Department of EE, and the authorities of IIEST, Shibpur, towards this work is also gratefully acknowledged.

\section{References}

[1] Gieras J 1994 Linear induction drives. Oxford: Clarendon Press

[2] Hellinger R and Mnich P 2009 Linear motor-powered transportation: history, present status and future outlook. Proc. IEEE 97: 1892-1900

[3] Gercek A and Karsh V 2009 Performance prediction of the single-sided linear induction motors for transportation considers longitudinal end effect by using analytic method. Contemp. Eng. Sci. 2: 95-104

[4] Ghalavand B S, Zadeh S V and Isfahani A H 2010 An improved magnetic equivalent circuit model for iron-core linear permanent-magnet synchronous motors. IEEE Trans. Magn. 46: 112-120

[5] Vaez-Zadeh S and Isfahani A H 2006 Multiobjective design optimization of air-core linear permanent-magnet synchronous motor for improved thrust and low magnet consumption. IEEE Trans. Magn. 42: 446-452

[6] Pillay P and Krishnan R 1989 Modeling, simulation, and analysis of permanent-magnet motor drives part $\mathrm{i}$ : the permanent-magnet synchronous motor drive. IEEE Trans. Ind. Appl. 25: 265-273

[7] Corsi N, Coleman R and Piaget D 2007 Status and new development of linear drives and subsystems. In: Proceedings of the International Symposium of Linear Drives for Industrial Applications, vol. 6

[8] Gieras J F and Piech Z J 2000 Linear syncronous motor: transportation and automation system. Boca Raton, CRC Press, p. 6

[9] Yamamura S 1978 Theory of linear induction motor. Tokyo, Tokyo Press

[10] Gieras J and Godkin M 2001 Status of permanent magnet linear motor in US. In: Proceedings of the International Symposium of Linear Drives for Industrial Applications, vol. 3

[11] Yoshimura T, Rim H, Watada M, Toni S and Ebiharai D 1995 Analysis of the reduction of detent force in a permanent magnet linear synchronous motor. IEEE Trans. Magn. 31: 3728-3730

[12] Hsieh M-F and Hu K-H 2014 Design and analysis of tubular permanent magnet linear wave generator. Sci. World J. vol. 2014 
[13] Jong K W and Murphy B C 2004 Development of a novel direct-drive tubular linear brushless permanent magnet motor. Int. J. Control Autom. Syst. 2: 279-288

[14] Baud A, Brichaux C Y R and Haeringi R E 1992 Tubular motor winding device for blinds, roller shutters or the like. Publication number US5105871 A

[15] Postacchini D 2002 Tubular motor reducer for winding roller shutters and sunblinds integrated with anti-fall device. Publication number EP0969180 A2

[16] Gasparrini P and Postacchini D 2012 Epicyclic reduction gear with multiple modular stages for tubular motor reducers operating winding roller shutter, roller shades and the like. Publication number US 8277358 B2

[17] Say M G 1983 Performance and design of alternating current machines. London: M/s.Pitman
[18] Mukherjee B K 2004 Design, fabrication and testing of a LIM and simulation of its Robust control: ME Thesis, Deptartment of Electrical Engineering, B.E. College, D.U.

[19] Sawhney A K 2006 Electrical machine design. Delhi, Dhanpat Rai and Co

[20] Trumper D L and Williams M E 1996 Design and analysis framework for linear permanent-magnet machines. IEEE Trans. Ind. Appl. 32: 371-379

[21] Powell R G 1990 Electromagnetism. In: Drabble G E (Ed.) Foundation of engineering. UK: Macmillan

[22] Mukherjee B, Sengupta M and Sengupta A 2004 Design, fabrication, testing and finite element analysis of a lab-scale LIM. In: Proceedings of IEEE Indicon, IIT Kharagpur, pp. 586-589 